\title{
Morphing of Bistable Composite Laminates Using Distributed Piezoelectric Actuators
}

\author{
Marie-Laure Dano, Mathilde Jean-St-Laurent, and Adam Fecteau \\ Department of Mechanical Engineering, Université Laval, Quebec City, QC, Canada G1V OA6 \\ Correspondence should be addressed to Marie-Laure Dano, mldano@gmc.ulaval.ca \\ Received 15 December 2011; Accepted 20 February 2012 \\ Academic Editor: Michael W. Hyer
}

Copyright ( $) 2012$ Marie-Laure Dano et al. This is an open access article distributed under the Creative Commons Attribution License, which permits unrestricted use, distribution, and reproduction in any medium, provided the original work is properly cited.

\begin{abstract}
The use of bistable unsymmetric cross-ply laminates for morphing application has received growing attention in the last few years. So far, most studies use large rectangular piezoelectric Macro Fiber Composite (MFC) patches bonded at the center of the laminate to induce snap-through. However, the use of large rectangular MFC patches bonded in the center of the laminates significantly influences the shape of the laminate by greatly reducing the curvature at the midsection of the laminate where the MFC patches are bonded. This paper presents a study where narrow cocured MFC strips distributed over the entire surface are used to induce snap-through of unsymmetric cross-ply laminates. This MFC configuration allows having a more uniform curvature in the laminate. Since the strips are bonded on both sides, reverse snap-through should be obtained. The study was both theoretical and experimental. A finite element nonlinear analysis was used to predict the two stable cylindrical configurations and the snapthrough induced by MFC actuation. For the experimental study, a laminate-MFC structure was manufactured and tested. The shapes were measured using a 3D image correlation system as a function of applied voltage. Good correlations for the cylindrical shape and displacement field were observed.
\end{abstract}

\section{Introduction}

The use of bistable composites for morphing application has received growing attention the last few years. The key characteristic of bistable structures is that they possess two stable equilibrium shapes and that they can be changed from one shape to the other by a simple snap-through action. Morphing can be obtained by alternating between these two shapes. Well-known bistable structures are unsymmetrically laminated composite plates [1-4]. For example, a two-layer $[0 / 90]_{T}$ laminate that is flat at its elevated cure temperature, as in Figure 1(a), cools from its cure temperature to have two equilibrium configurations. One configuration is cylindrical with a large curvature in the $x$-direction, Figure $1(\mathrm{~b})$. The other configuration is cylindrical with a large curvature in the $y$-direction, Figure $1(\mathrm{c})$. The curvatures for the two configurations are equal but of opposite signs, and the laminate can be changed from one configuration to the other by a simple snap-through action initiated by applying equal and opposite moments to the edges of the laminate. Analysis indicates that there is a third equilibrium configuration which is a saddle shape, Figure 1(d). However, this shape is unstable and is not observed in practice. Due to their bi stability, unsymmetric laminates are good candidates for morphing applications and most of the work done in this field involves this kind of laminates, in particular cross-ply unsymmetric laminates [4-12]. The main advantage of using bistable structures is that large shape change can be obtained with little power consumption since the application of forces is needed only to induce snap-through, not to hold the structure into a deformed configuration. Several theoretical and experimental studies have been reported to understand and predict actuator-induced snap-through of unsymmetric laminates [5-9]. Models based on Rayleigh-Ritz approach [5-8] are useful for design purposes to carry out parametric studies, and finite element models [9] are useful to predict more accurately the behaviour of the laminate/actuator system but are much more time consuming. Theoretical and experimental studies showed that unsymmetric laminates could be changed from one shape to the other using either 


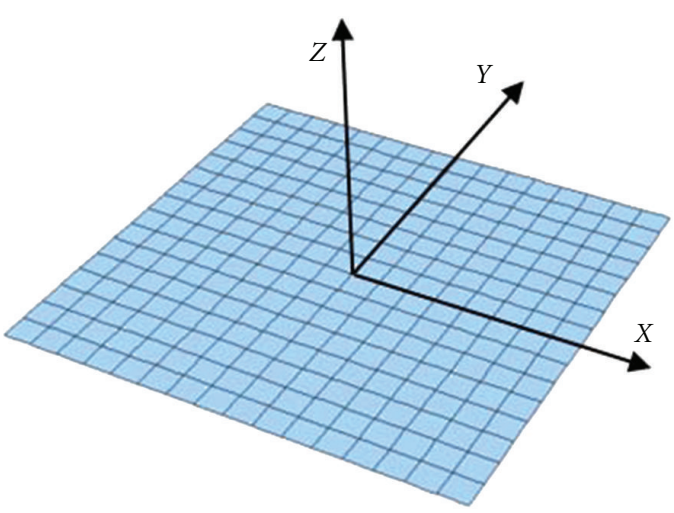

(a)

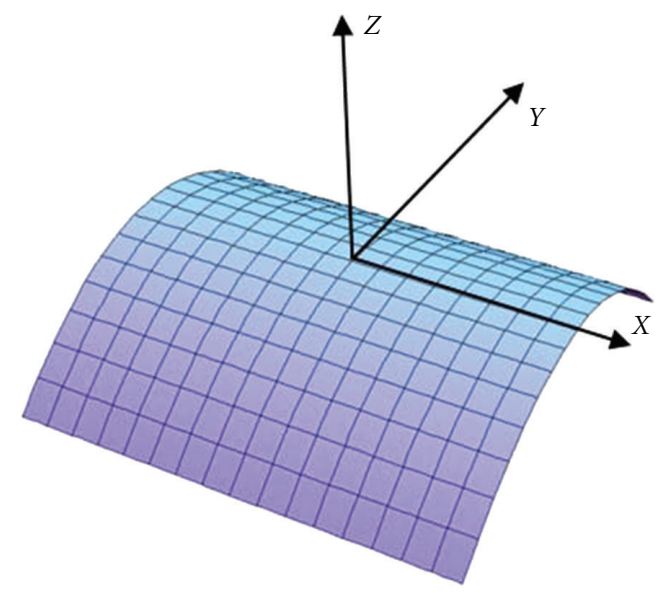

(c)

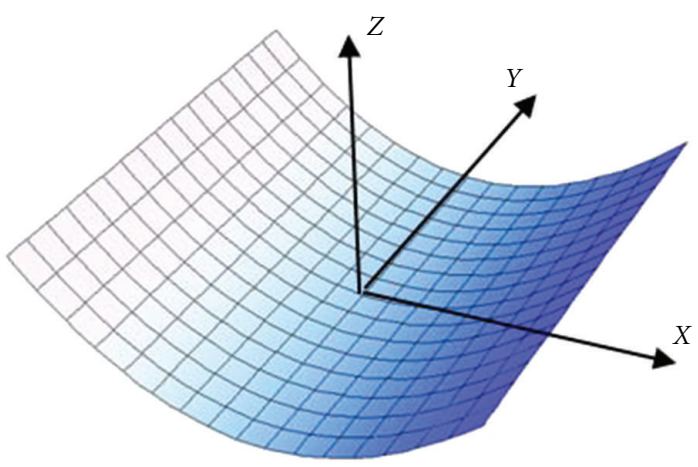

(b)

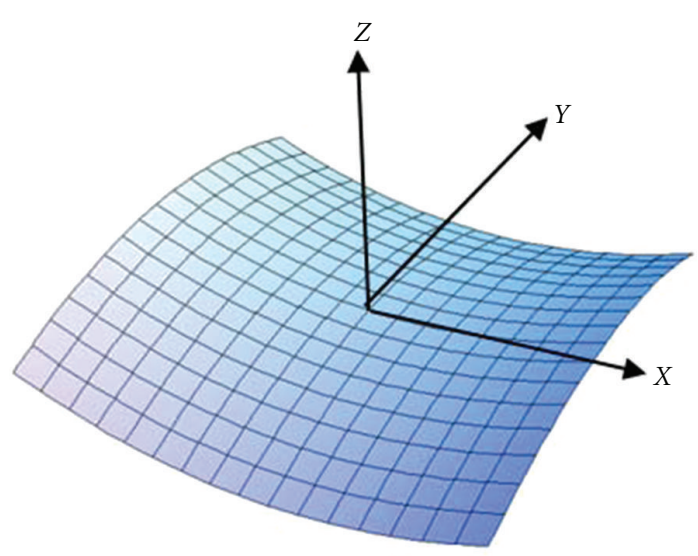

(d)

FIGURE 1: Equilibrium shapes of a $[0 / 90]_{T}$ laminate. (a) Cure temperature: flat shape. (b) Room temperature: stable cylindrical shape with curvature in the $x$-direction. (c) Room temperature: stable cylindrical shape with curvature in the $y$-direction. (d) Room temperature: unstable saddle shape.

Shape Memory Alloy (SMA) wires [6, 7] or piezoelectric Macro Fiber Composite (MFC) patches [5, 9] attached on one side and that it could be predicted fairly well. However, reverse snap-through could not be achieved because the actuator was just located on one side. Lately, Schultz et al. [8] added an MFC patch on the other side of the laminate and showed that reverse snap-through could be induced using the second actuator. So far, investigators have all used rectangular MFC patches bonded in the center of the laminates $[5,8,9]$. This kind of patches significantly influences the shape of the laminate by greatly reducing the overall curvature [5]. When used in pair as in [8], the midsection of the laminate becomes quite flat and most of the curvature occurs along the edges and at the corners. It is thought that other types of MFC configuration, such as narrow MFC strips that could be distributed on the entire surface, may be more suitable and may produce more interesting results. The work discussed here will investigate this idea.

This paper begins in the first section with a general description of the problem that will be investigated, that is, the change of shape of a two-layer unsymmetric cross-ply $[0 / 90]_{T}$ laminate using cocured MFC strips distributed over the top and bottom surfaces. In the following section, a finite element model is presented and used to predict, in a first step, the behaviour of the laminate-MFC structure as it cools from cure temperature to room temperature and, in a second step, the snap-through of the laminate induced by actuating the MFC strips. After the model is presented, the results of the analysis are presented and discussed. Next, the experimental study that was conducted to validate the model predictions is presented. Experiments that consisted in measuring the shape of the laminate as voltage was applied to the MFC actuators are described. Finally, the paper concludes with suggestions for future work.

\section{Problem Description}

In this study, the behavior of a $[0 / 90]_{T}$ laminate with MFC actuator strips bonded over the top and bottom surfaces is investigated. The composite structure is a square laminate with side length of $190 \mathrm{~mm}$ and thickness of $0.3 \mathrm{~mm}$. The laminate is made of two layers of M46 J $(12 \mathrm{~K}) / \mathrm{RS}-36$ prepreg. Twelve MFC strips with $160 \mathrm{~mm}$ by $10 \mathrm{~mm}$ side lengths and a $0.3 \mathrm{~mm}$ thickness (M14003-P1) are bonded 


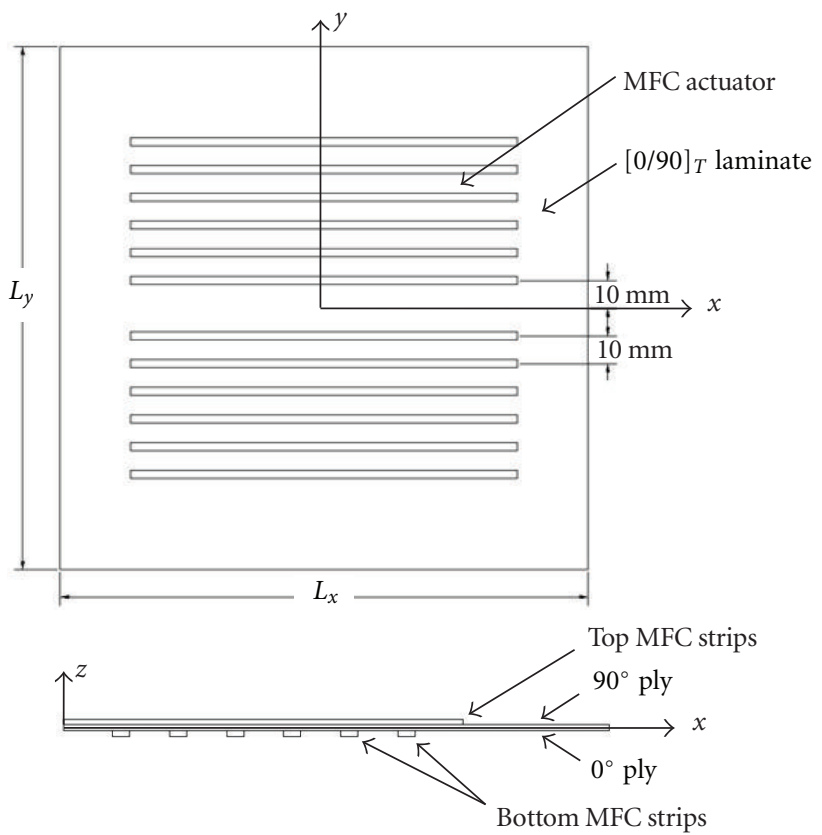

Figure 2: Laminate/MFC structure description.

TABLE 1: Carbon-epoxy prepreg and MFC material properties.

\begin{tabular}{lcc}
\hline Property & M46 J $(12 \mathrm{~K}) / \mathrm{RS}-36$ & MFC actuator \\
\hline$E_{1}(\mathrm{GPa})$ & 231.1 & 30.3 \\
$E_{2}(\mathrm{GPa})$ & 5.64 & 15.9 \\
$G_{12}(\mathrm{GPa})$ & 3.01 & 5.515 \\
$\nu_{12}$ & 0.2 & 0.31 \\
$\alpha_{1}\left(10^{-6} /{ }^{\circ} \mathrm{C}\right)$ & -0.85 & 5.9 \\
$\alpha_{2}\left(10^{-6} /{ }^{\circ} \mathrm{C}\right)$ & 33.0 & 29.6 \\
$d_{11}(\mathrm{pm} / \mathrm{V})$ & - & 360 \\
$d_{12}(\mathrm{pm} / \mathrm{V})$ & - & -190 \\
\hline
\end{tabular}

on each side of the laminate during the lay-up process. The laminate/MFC assembly is put on a flat plate and cured. Figure 2 shows the plate configuration. The MFC strips bonded on the top surface are aligned in the $x$ direction whereas the MFC strips bonded on the bottom surface are aligned in the $y$-direction. Only the active part of the MFC ( $3 \mathrm{~mm}$ by $140 \mathrm{~mm}$ ) is represented in the figure. Spacing is larger at the center to have enough room to clamp the structure during testing. Table 1 presents the materials properties.

The objective of the paper is to investigate if using MFC strips distributed over the top and bottom surfaces of a cross-ply laminate is suitable to obtain a reversible bistable structure with cylindrical shapes. This is done in two parts. First, a finite element model is developed to predict (i) the shape of the laminate/MFC structure due to cooling from cure temperature and (ii) the response of the laminate/MFC structure as voltage is applied to the MFC strips. Next, experimental work is conducted to validate the model predictions.

\section{Finite Element Analysis}

The laminate/MFC assembly was modeled using the ABAQUS finite element software. The square $[0 / 90]_{T}$ plate was modeled using approximately 2300 general purpose shell elements (S4R). The active part of the MFC strips was modeled using 47 S4R elements. Since the configuration studied has a total of twenty-four MFC strips, the finite element model used 3400 shell elements overall.

The shells elements used to model the MFC strips were offset from the midplane of the laminate shell elements by $0.3 \mathrm{~mm}$. The distance corresponds to half the laminate and MFC thickness. The strips are linked to the plate using TIE constraint. This approach follows the one used by Portela et al. [9].

The assembly was clamped at its central node. In order to obtain the different equilibrium shapes, small geometric imperfections need to be included $[3,11,12]$. The simplest way is to change slightly the side lengths of the laminate. In this case, the square laminate with a nominal side length of $190 \mathrm{~mm}$ was modeled as a rectangular plate with $189 \mathrm{~mm}$ by $191 \mathrm{~mm}$ side lengths.

The objectives of the finite element analysis are to predict the cured shape of the laminate/MFC assembly and to simulate the snap-through induced by applying voltage to the MFC actuators. To achieve this, geometrical nonlinearities have to be taken into account. The finite element analysis is performed in three steps.

In the first step, the cooling from cure temperature to room temperature is simulated. The initial temperature is equal to $177^{\circ} \mathrm{C}$. At this temperature, the laminate/MFC assembly is flat and stress free. A temperature change $\Delta T=$ $-152^{\circ} \mathrm{C}$ which represents the difference between room temperature and cure temperature is applied to all shell elements. The thermally induced deformation of the laminate/MFC assembly is computed using a simple *STATIC nonlinear analysis. The two stable cylindrical shapes can be computed by using either $\left(L_{x}=189 \mathrm{~mm}, L_{y}=191 \mathrm{~mm}\right)$ or $\left(L_{x}=\right.$ $191 \mathrm{~mm}, L_{y}=189 \mathrm{~mm}$ ) for the side lengths.

In the second step, voltage is applied and the snapthrough of the laminate induced by MFC actuation is simulated. In the literature, two procedures have been successfully used to simulate snap-though, namely, the RIKS and STABILIZE procedure $[9,12]$. In this study, the STABILIZE procedure was used. Since general purpose shell elements are used to model the MFC actuators, the electric field cannot be applied directly as boundary conditions. Therefore, voltage is applied through the temperature field using the thermal deformation capabilities of ABAQUS. The coefficient of thermal expansion for the MFC actuators had to be modified to take into account the piezoelectric and thermal expansion effects. The two-dimensional modeling equation for an MFC pooled in the 1-direction under a state of plane stress is given by

$$
\begin{gathered}
\varepsilon_{1}=S_{11} \sigma_{1}+S_{12} \sigma_{2}+\alpha_{1} \Delta T+d_{11} E_{1}, \\
\mathcal{E}_{2}=S_{12} \sigma_{1}+S_{22} \sigma_{2}+\alpha_{2} \Delta T+d_{12} E_{1}, \\
\varepsilon_{6}=S_{66} \sigma_{6},
\end{gathered}
$$


TABLE 2: Summary of the analysis steps.

\begin{tabular}{|c|c|c|c|}
\hline & Step 1 & Step 2 & Step 3 \\
\hline \multirow[t]{2}{*}{ Loading } & $\Delta T=-152^{\circ} \mathrm{C}$ & $\Delta T=-152^{\circ} \mathrm{C}$ & $\Delta T=-152^{\circ} \mathrm{C}$ \\
\hline & & $\Delta V=1500 \mathrm{~V}$ & $\Delta V=0 \mathrm{~V}$ \\
\hline \multirow[t]{2}{*}{ Properties } & $\alpha_{1}^{*}=\alpha_{1}$ & $\alpha_{1}^{*}=\alpha_{1}^{*}(\Delta \mathrm{V})$ & $\alpha_{1}^{*}=\alpha_{1}^{*}(\Delta V)$ \\
\hline & $\alpha_{2}^{*}=\alpha_{2}$ & $\alpha_{2}^{*}=\alpha_{2}^{*}(\Delta \mathrm{V})$ & $\alpha_{2}^{*}=\alpha_{2}^{*}(\Delta V)$ \\
\hline \multirow[t]{2}{*}{$\begin{array}{l}\text { Analysis } \\
\text { type }\end{array}$} & $\begin{array}{c}{ }^{*} \text { step } \\
\text { nlgeom }=\text { yes }\end{array}$ & $\begin{array}{c}{ }^{*} \text { step, } \\
\text { nlgeom = yes }\end{array}$ & $\begin{array}{c}\text { *step, } \\
\text { nlgeom = yes }\end{array}$ \\
\hline & *static & *static, stabilize & *static \\
\hline Results & $\begin{array}{c}\text { Cylindrical } \\
\text { shape I at } 25^{\circ} \mathrm{C}\end{array}$ & $\begin{array}{c}\text { Cylindrical shape } \\
\text { II at } 25^{\circ} \mathrm{C} \text { with } \\
\text { voltage }\end{array}$ & $\begin{array}{l}\text { Cylindrical shape } \\
\text { II at } 25^{\circ} \mathrm{C}\end{array}$ \\
\hline
\end{tabular}

where $\varepsilon_{i}$ are the strain components, $S_{i j}$ are the compliance matrix components, $\sigma_{j}$ are the stress components, $\alpha_{i}$ are the coefficients of thermal expansion, $d_{i j}$ are the effective piezoelectric constants, $\Delta T$ is the temperature change, and $E_{1}$ is the electric field. The electric field is equal to $\Delta V / w$, where $\Delta V$ is the applied voltage and $w$ is the electrode spacing. The first two lines of the equation can be rewritten as

$$
\begin{aligned}
& \varepsilon_{1}=S_{11} \sigma_{1}+S_{12} \sigma_{2}+\left(\alpha_{1} \frac{\Delta T}{\Delta V}+\frac{d_{11}}{w}\right) \Delta V, \\
& \varepsilon_{2}=S_{12} \sigma_{1}+S_{22} \sigma_{2}+\left(\alpha_{2} \frac{\Delta T}{\Delta V}+\frac{d_{12}}{w}\right) \Delta V .
\end{aligned}
$$

By introducing modified coefficients of thermal expansion $\alpha_{i}^{*}$, (2) can be expressed as

$$
\begin{aligned}
& \varepsilon_{1}=S_{11} \sigma_{1}+S_{12} \sigma_{2}+\alpha_{1}^{*} \Delta V, \\
& \varepsilon_{2}=S_{12} \sigma_{1}+S_{22} \sigma_{2}+\alpha_{2}^{*} \Delta V,
\end{aligned}
$$

where the modified coefficients of thermal expansion $\alpha_{i}^{*}$ are equal to

$$
\begin{aligned}
& \alpha_{1}^{*}=\alpha_{1} \frac{\Delta T}{\Delta V}+\frac{d_{11}}{w}, \\
& \alpha_{2}^{*}=\alpha_{2} \frac{\Delta T}{\Delta V}+\frac{d_{12}}{w} .
\end{aligned}
$$

The modified coefficients of thermal expansion account for the effects of thermal expansion caused by $\Delta T$ and the piezoelectric expansion caused by $\Delta V$. In the equation, the electrode spacing $w$ is equal to $0.5 \mathrm{~mm}$, the applied temperature change $\Delta T$ is equal to $-152^{\circ} \mathrm{C}$ (as it was the case in the first step) and the applied voltage $\Delta V$ varies from 0 to $1500 \mathrm{~V}$. The modified coefficients of thermal expansion are entered in ABAQUS as temperature-dependant properties but with the temperature field replaced by voltage.

In the third and last step of the analysis, $\Delta T$ is still equal to $-152^{\circ} \mathrm{C}$ and voltage is removed $(\Delta V=0)$. The shape obtained is the second stable cylindrical configuration.

Details of the different steps used in the analysis are represented in Table 2. The results of the analysis are presented in the Section 4.

\section{Numerical Results}

As described above, step 1 of the finite element analysis predicts shapes of the laminate/MFC structure at room temperature. The results obtained with $L_{x}=191 \mathrm{~mm}$ and $L_{y}=189 \mathrm{~mm}$ are presented in Figure 3(a). The configuration is a cylindrical shape with its generator parallel to the $x$ axis. Figure 3(b) illustrates the shape obtained with $L_{x}=$ $189 \mathrm{~mm}$ and $L_{y}=191 \mathrm{~mm}$. It is a cylindrical shape with its generator parallel to the $y$-axis. In both cases, the out-ofplane displacements have the same magnitude. The out-ofplane displacement increases regularly from the center to the edges with no flat area in the center as observed when using one single large MFC patch on each side [8].

In step 2, the actuation of the MFC strips placed on the bottom surface of the laminate is simulated. As voltage is applied, the laminate curvature and the out-of-plane displacement decrease until snap-through occurs as can be observed in Figure 4. The figure shows the out-of-plane displacement at the corners as a function of applied voltage. At the beginning of the step, the laminate is in configuration I of Figure 3(a) (point A). As voltage increases, the out-ofplane displacement decreases. Past point $\mathrm{B}$, there is a sudden change in the magnitude of the out-of-plane displacement which indicates that snap-though has occurred (jump from point $\mathrm{B}$ to point $\mathrm{C}$ ). The jump corresponds to an applied voltage $\Delta V=1180 \mathrm{~V}$. The laminate is now in configuration II of Figure 3(b). After snap-through, voltage continues increasing up to $1500 \mathrm{~V}$ which induces a slight decrease in the out-of-plane displacement (point D). In Figure 5, the laminate shapes at $\Delta V=0$ (point A), $\Delta V=1180 \mathrm{~V}$ (point $\mathrm{B}$ ), and $\Delta V=1500 \mathrm{~V}$ (point $\mathrm{D}$ ) are presented. Just before snap-through occurs, the laminate is almost flat except at the edges (point B). The edge displacements are small but opposite in sign similar to the unstable saddle shape of Figure $1(\mathrm{~d})$.

Finally, in step 3, voltage is removed. The laminate stays in configuration II. Compared to the shape at point D in Figure 5, the out-of-plane displacement has increased by about $8 \%$ (see Figure 6).

\section{Experimental Results}

5.1. Laminate-MFC Structure Manufacturing. The $[0 / 90]_{T}$ laminate was cured and the twenty-four MFC strips bonded in one single step. First, the two prepreg plies were cut and stacked. Then, twelve MFC were bonded on one surface using Loctite (HP-E120) two-part epoxy adhesive and hold in position using flash tape. The laminate and MFC dimensions and configuration are indicated in Figure 2. A layer of release ply was put on the top. The laminate was laid on a flat tool with the MFC strips against the flat tool. Next, the other twelve MFC were bonded on the top surface of the laminate and hold in place with flash tape. A layer of release ply was put on the top. The laminate-MFC assembly was cured in a vacuum bag at $177^{\circ} \mathrm{C}$ following the prepreg cure cycle. The laminate-MFC assembly was removed from the oven and vacuum bag. As predicted, the structure has two cylindrical shapes. The first cylindrical shape has 


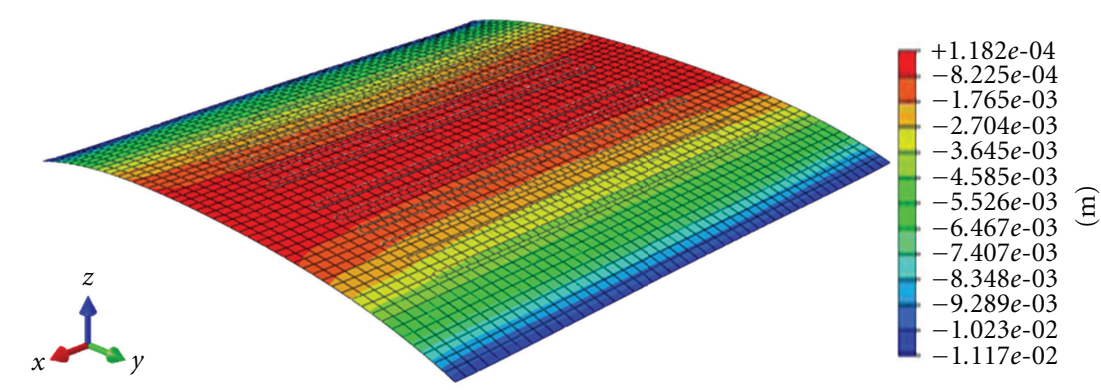

(a)

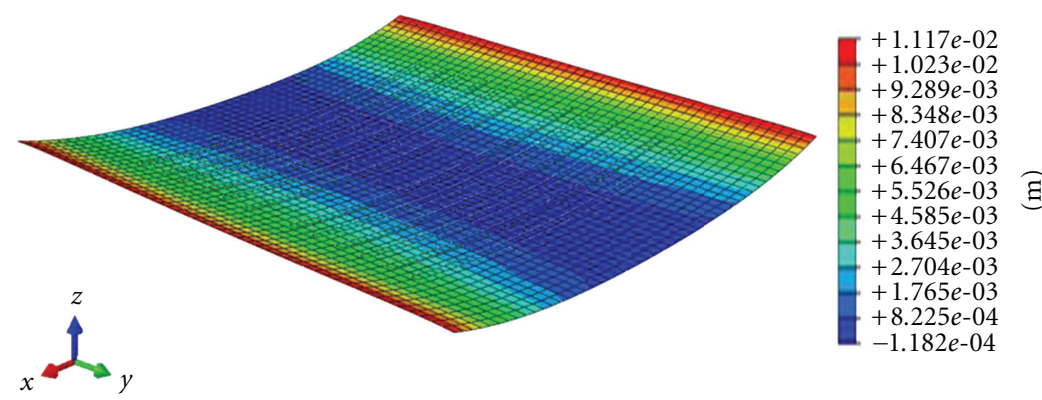

(b)

FIGURE 3: Equilibrium configurations predicted by the finite element model (step 1). (a) Equilibrium shape I $\left(L_{x}=191 \mathrm{~mm}, L_{y}=189 \mathrm{~mm}\right)$. (b) Equilibrium shape II $\left(L_{x}=189 \mathrm{~mm}, L_{y}=191 \mathrm{~mm}\right)$.

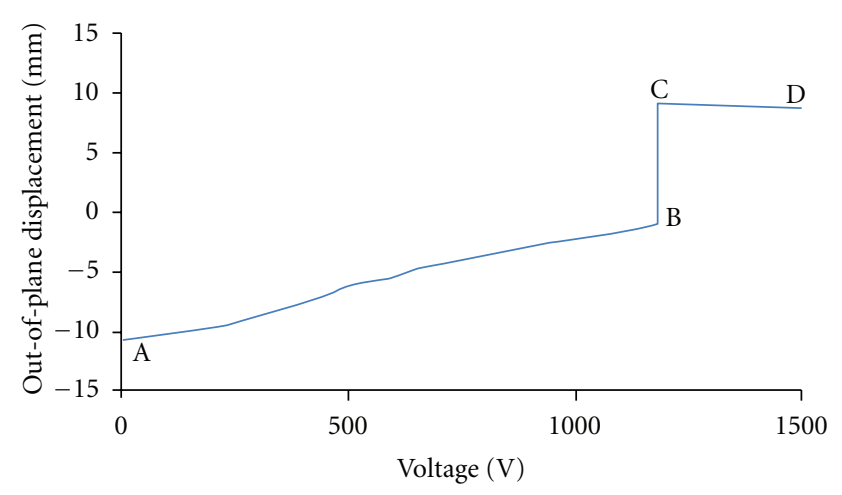

Figure 4: Predicted out-of-plane displacement versus applied voltage (step 2).

an out-of-plane displacement of about $10 \mathrm{~mm}$ and a nice and uniform curvature (see Figure 7). By a snap-through action, the second cylindrical shape can be obtained but the laminate does not stay in this configuration. It seems that imperfections due to manufacturing, such as uneven MFC spacing, adhesive excess, uneven ply thickness, and fiber misalignment, prevent the laminate from having a second stable cylindrical shape. Thus, the ability of the laminateMFC structure to exhibit two stable shapes is highly sensitive to manufacturing imperfections.

5.2. Experimental Setup and Test Procedure. The experimental setup to study the behavior of the laminate-MFC structure subject to applied voltage consists mainly in a voltage supply,
Dasylab data acquisition system, a stand to hold the laminate, and a $3 \mathrm{D}$ image correlation system to measure the shape of the laminate.

The image correlation equipment used to measure the displacement fields during the tests is the ARAMIS system from Trilion. The system is composed of two 4 Megapixels digital CCD cameras. Before testing, a random pattern is applied to the specimen surface. During testing, images of the specimen are taken by the two CCD cameras. Then, the system combines the two images to determine the coordinates of each facets on the specimen surface. From the coordinates, the $x$-, $y$-, $z$-displacements are computed. The displacement fields at different applied voltage can be visualized. A $250 \times 200 \mathrm{~mm}$ calibration volume was used for the measurements.

After the electrical wires were connected to the MFCs and the pattern was applied on the laminate surface, the structure was fixed at its center on the test fixture (see Figure 8). With the laminate-MFC structure in configuration I, voltage was applied. The application of voltage was controlled by the software Dasylab. Voltage was increased from 0 to $1500 \mathrm{~V}$ by $30 \mathrm{~V}$ increments every five seconds. Pictures of the laminate were taken at zero voltage and after each increment by the ARAMIS system.

5.3. Results. After the experiment, the pictures were processed to calculate the $3 \mathrm{D}$ coordinates of facets on the plate surface using photogrammetric principles. Based on these $3 \mathrm{D}$ coordinates, the $3 \mathrm{D}$ displacement and the shape of the plate were calculated for different voltages. The 


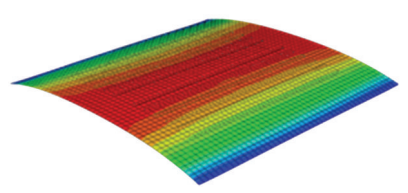

(a)

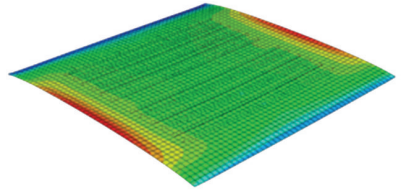

(b)

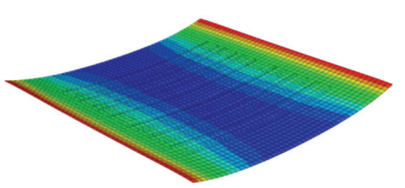

(c)

FIGURE 5: Predicted shapes for different applied voltage levels (step 2). (a) Shape at point $\mathrm{A}(\Delta V=0)$. (b) Shape at point B $(\Delta V=1180 \mathrm{~V})$. (c) Shape at point $\mathrm{D}(\Delta V=1500 \mathrm{~V})$.
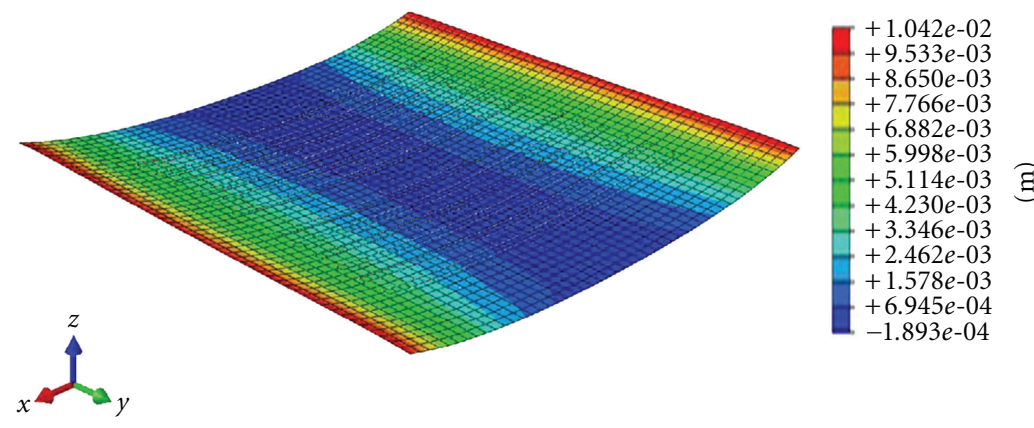

FIGURE 6: Predicted shape after snap-though with no applied voltage (step 3).

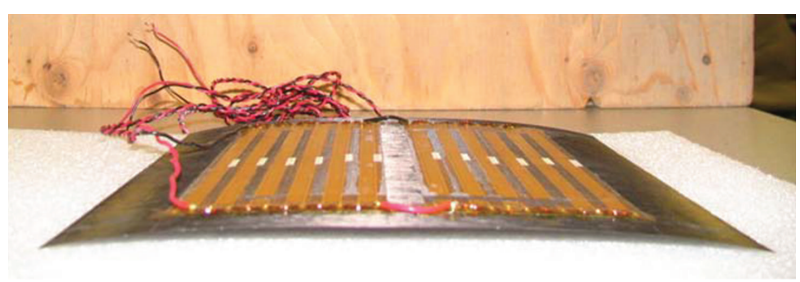

Figure 7: Laminate-MFC assembly.

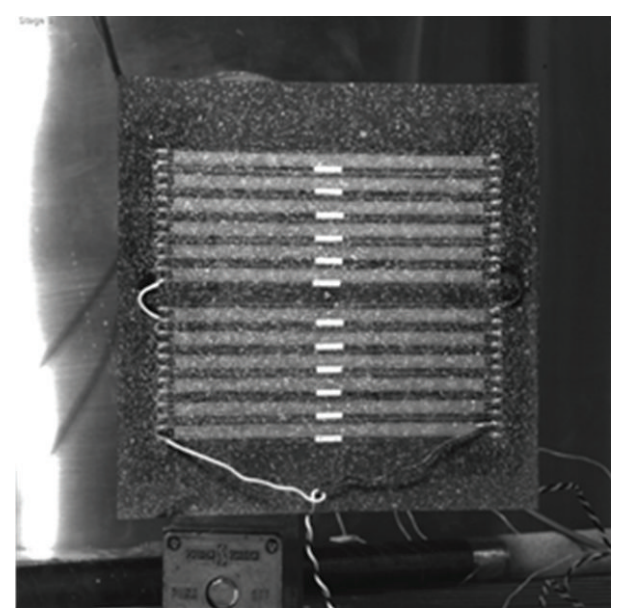

Figure 8: Laminate-MFC structure with speckle pattern fixed on the stand.

results can then be displayed as graphics of the out-of-plane displacement that can be compared directly to the finite element predictions.

Figure 9 shows the out-of-plane displacements obtained for the laminate at zero voltage both experimentally (a) and numerically (b). As can be seen, the two shapes are very similar. The maximum displacements are $10.24 \mathrm{~mm}$ and $11.17 \mathrm{~mm}$, respectively, for the experimental and theoretical shapes. As can be noticed in the figure, measurement was not possible at a few places on the laminate surface. Most of them correspond to the location of the electrical wires.

Figure 10 shows the laminate at different applied voltages. As expected, the laminate curvature and out-of-plane displacements decrease with applied voltage. At $1500 \mathrm{~V}$, the laminate is quite flat except at the edges where the displacements are very small with a magnitude around $2.5 \mathrm{~mm}$ and opposite in sign. It is very similar to the shape obtained by Figure 5(b) just before snap-through occurs. However, the change of shape could not be obtained experimentally. It is probably due to manufacturing defects.

Figure 11 compares the predicted and measured out-ofplane displacements at the corners. The measured out-ofplane displacement is an average of the values at the four corners. As can be observed, the comparison is quite good up to $1180 \mathrm{~V}$. The values and slopes are close. After $1180 \mathrm{~V}$, the finite element analysis predicts that snap-through occurs and the displacement jumps suddenly to $9 \mathrm{~mm}$. However, experimentally, the laminate does not show this behavior. At that voltage, the out-of-plane displacement is larger and continues decreasing until voltage reaches the maximum operational value of $1500 \mathrm{~V}$. At this voltage, the out-ofplane displacement at the corners has a really small value $(-1.8 \mathrm{~mm})$ and snap-through should have been imminent.

\section{Concluding Remarks}

This study investigated the use of MFC strips distributed over the top and bottom surfaces of a cross-ply unsymmetric $[0 / 90]_{T}$ laminate to obtain a reversible bistable structure. The 

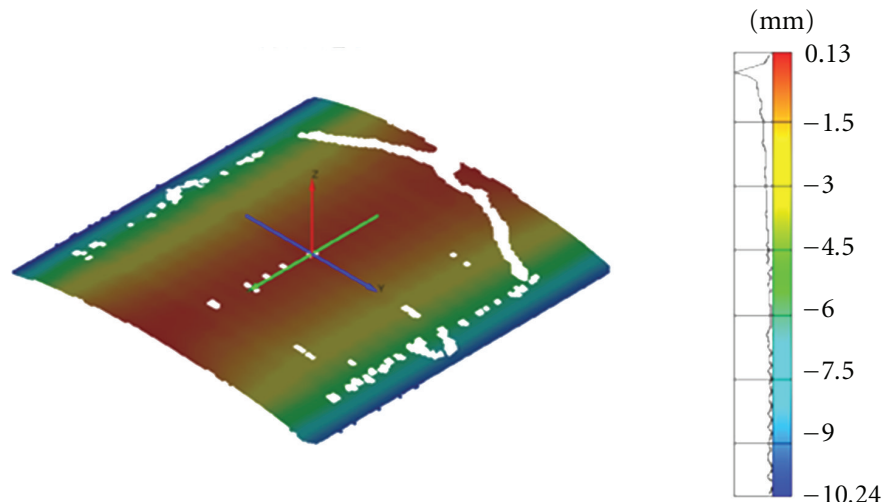

(a)
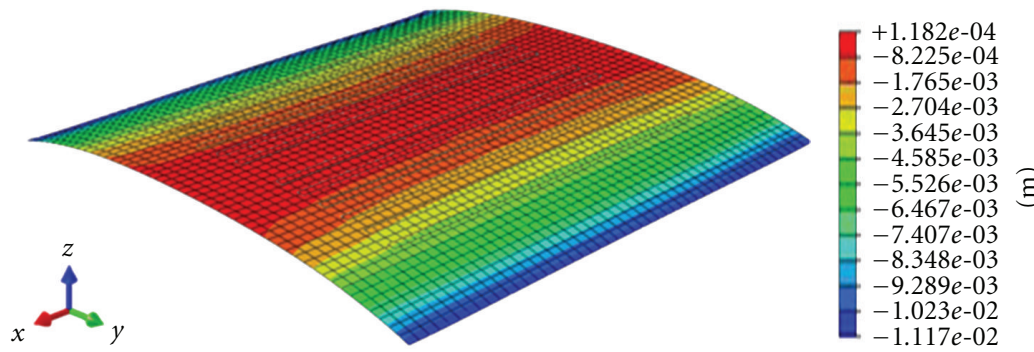

(b)

Figure 9: Comparison between the measured and predicted out-of-plane displacement. (a) Measured out-of-plane displacement. (b) Predicted out-of-plane displacement.

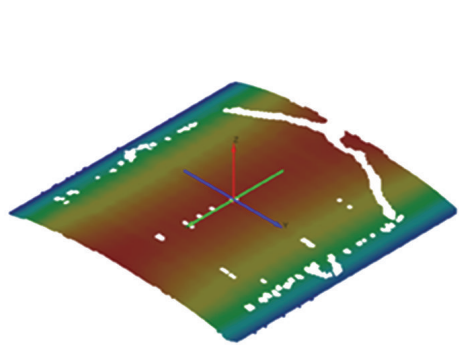

(a)

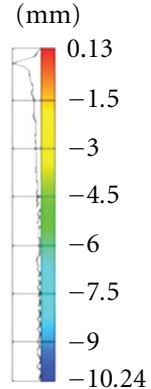

10.24
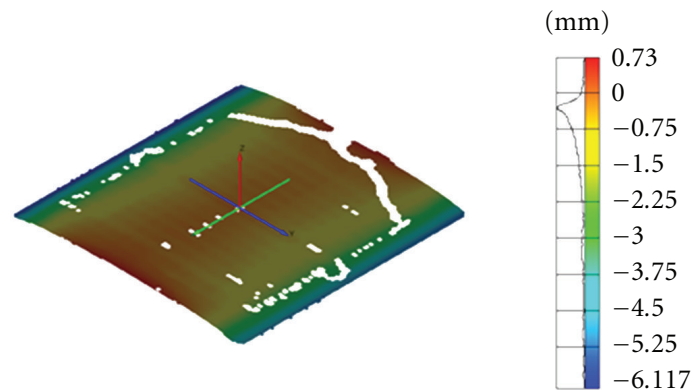

(b)

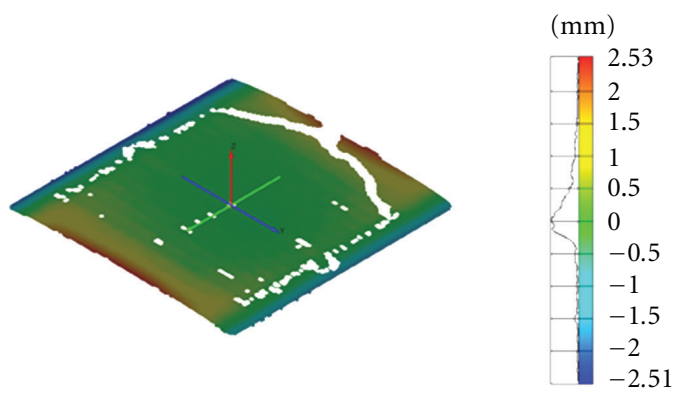

(c)

FIGURE 10: Measured out-of-plane displacements at different applied voltages. (a) $\Delta V=0 \mathrm{~V}$. (b) $\Delta V=750 \mathrm{~V}$. (c) $\Delta V=1500 \mathrm{~V}$. 


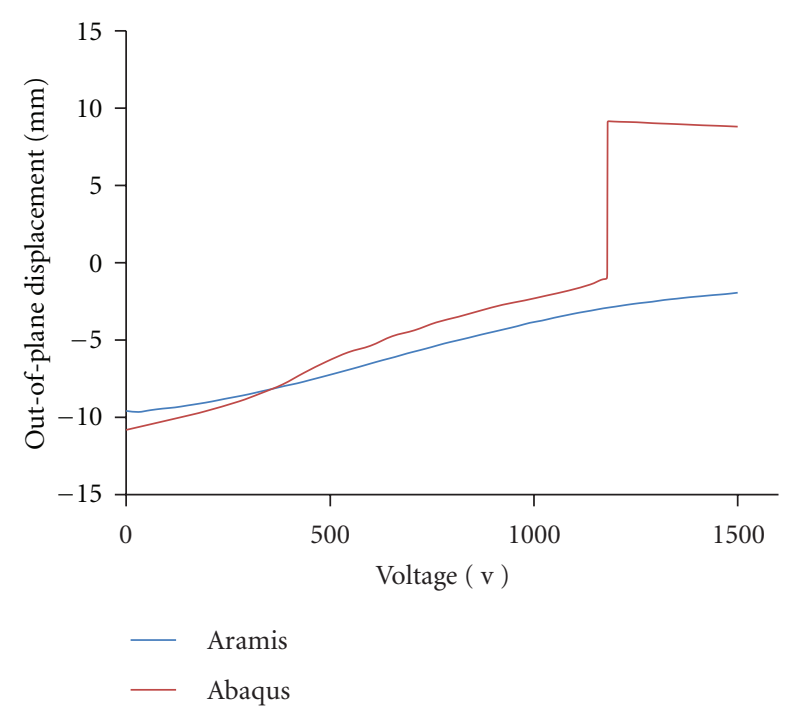

FIGURE 11: Comparison between predicted and measured out-ofplane displacements at the corners.

MFC strips were bonded and cocured with the laminate. Finite element analyses and experimental work have been performed.

The use of distributed MFC strips allows the laminate to have a smooth cylindrical shape. Of course, since the MFC strips add stiffness to the structure, the laminate curvature is smaller than without MFC strips. The finite element analysis predicts that the laminate-MFC structure exhibits two cylindrical shapes and that snap-though can be induced by applying $1180 \mathrm{~V}$ to the MFC actuators. Reversible snap-though can of course be obtained. However, the laminate-MFC structure that was manufactured exhibits only one stable cylindrical shape. The other cylindrical shape exists but the structure does not stay in this configuration. It is though that manufacturing defects such as excess glue, uneven MFC spacing, and uneven ply thickness are critical enough to lead to the loss of the bi-stability of the laminate. Further work needs to be conducted to study which parameter affects the most the stability of the second configuration.

The experimental work provided very interesting results since measurements of the displacement field were taken and could be compared to the predictions. Good correlations for the shape and out-of-plane displacement were obtained. The finite element model is able to capture quite well the behavior of the laminate-MFC structure subjected to applied voltage and temperature change.

In light of this study and past works results $[5,8,9]$ it is felt that MFC or piezoceramic actuators may not be the best choice to induce snap-through in unsymmetric laminates. They add stiffness to the laminate which induces a decrease in curvature, require high values of voltage, and can lead to the loss of bi-stability of the laminate. Future works should focus on investigating the use of other types of actuators that would be less intrusive and more efficient. Shape memory alloys as used in [7] may be finally a more promising alternative since they can develop large actuation force with small voltage, can be attached to the laminate without altering the shape or the bi-stability.

\section{Acknowledgment}

The authors would like to thank the National Sciences and Engineering Research Council of Canada (NSERC) for its financial support.

\section{References}

[1] M. W. Hyer, "The room-temperature shapes of four-layer unsymmetric cross-ply laminates," Journal of Composite Materials, vol. 16, no. 4, pp. 318-340, 1982.

[2] H. Akira and M. W. Hye, "Non-linear temperature-curvature relationships for unsymmetric graphite-epoxy laminates," International Journal of Solids and Structures, vol. 23, no. 7, pp. 919-935, 1987.

[3] M. L. Dano and M. W. Hyer, "Thermally-induced deformation behavior of unsymmetric laminates," International Journal of Solids and Structures, vol. 35, no. 17, pp. 2101-2120, 1998.

[4] M. L. Dano and M. W. Hyer, "The response of unsymmetric laminates to simple applied forces," Mechanics of Composite Materials and Structures, vol. 3, no. 1, pp. 65-80, 1996.

[5] M. R. Schultz and M. W. Hyer, "Snap-through of unsymmetric cross-ply laminates using piezoceramic actuators," Journal of Intelligent Material Systems and Structures, vol. 14, no. 12, pp. 795-814, 2003.

[6] W. Hufenbach, M. Gude, and L. Kroll, "Design of multistable composites for application in adaptive structures," Composites Science and Technology, vol. 62, no. 16, pp. 2201-2207, 2002.

[7] M. L. Dano and M. W. Hyer, "SMA-induced snap-through of unsymmetric fiber-reinforced composite laminates," International Journal of Solids and Structures, vol. 40, no. 22, pp. 59495972, 2003.

[8] M. R. Schultz, W. K. Wilkie, and R. G. Bryant, "Investigation of self-resetting active multistable laminates," Journal of Aircraft, vol. 44, no. 4, pp. 1069-1076, 2007.

[9] P. Portela, P. Camanho, P. Weaver, and I. Bond, "Analysis of morphing, multi stable structures actuated by piezoelectric patches," Computers and Structures, vol. 86, no. 3-5, pp. 347356, 2008.

[10] F. Mattioni, P. M. Weaver, K. D. Potter, and M. I. Friswell, "Analysis of thermally induced multistable composites," International Journal of Solids and Structures, vol. 45, no. 2, pp. 657675,2008

[11] M. Gigliotti, M. R. Wisnom, and K. D. Potter, "Loss of bifurcation and multiple shapes of thin [0/90] unsymmetric composite plates subject to thermal stress," Composites Science and Technology, vol. 64, no. 1, pp. 109-128, 2004.

[12] S. Tawfik, Xinyan Tan, S. Ozbay, and E. Armanios, "Anticlastic stability modeling for cross-ply composites," Journal of Composite Materials, vol. 41, no. 11, pp. 1325-1338, 2007. 

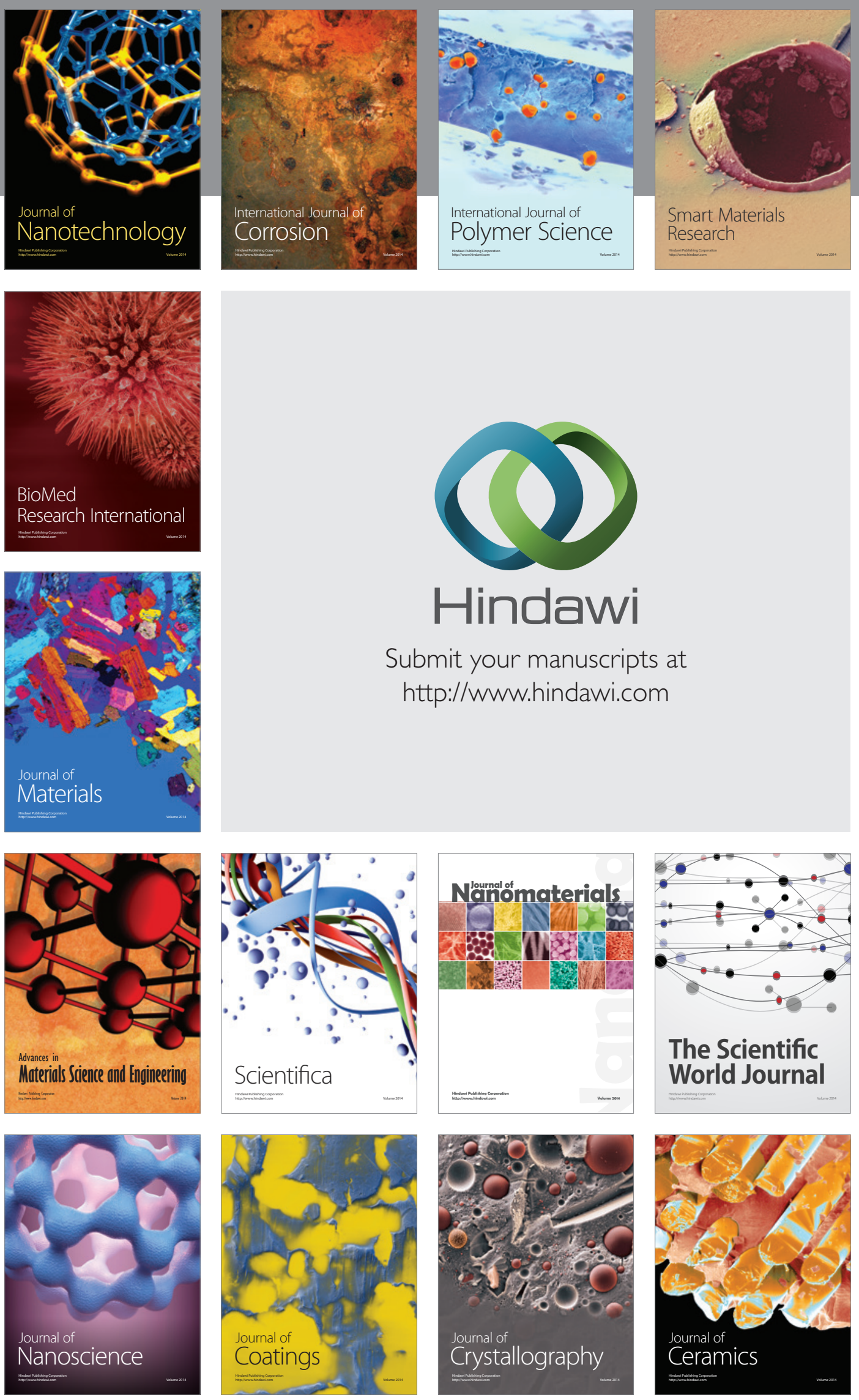

The Scientific World Journal

Submit your manuscripts at

http://www.hindawi.com

\section{World Journal}

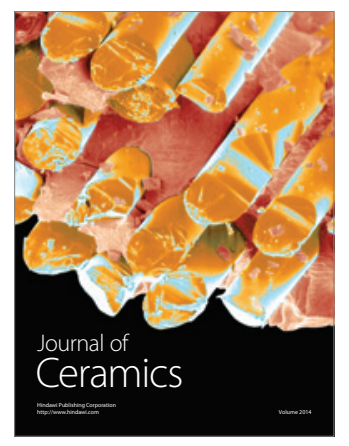

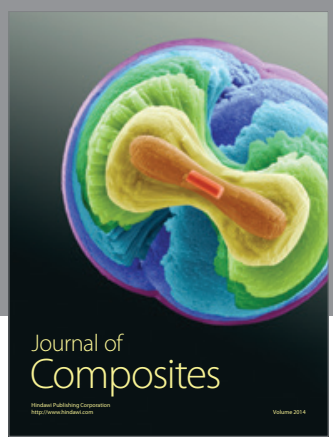
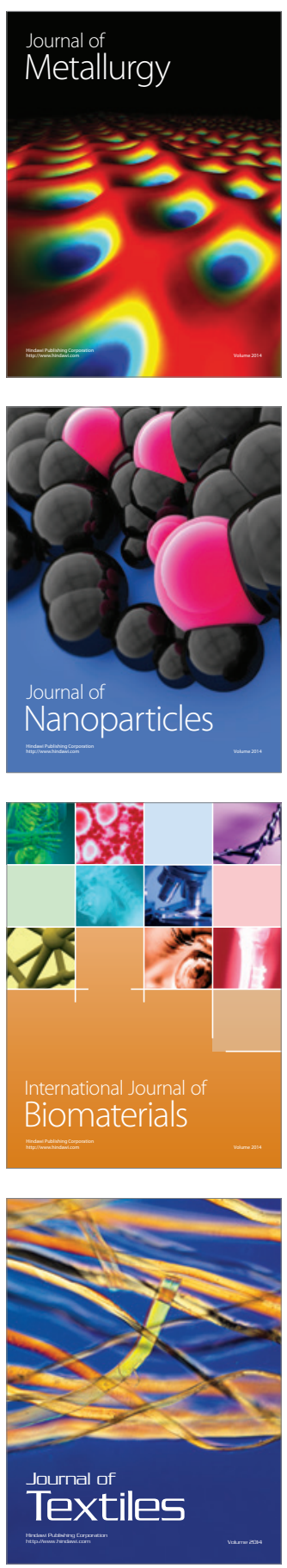